\title{
Perilaku Pemeliharaan Kesehatan Gigi Mulut Siswa SD Dengan dan Tanpa Usaha Kesehatan Gigi Sekolah (UKGS)
}

\author{
Ayumi Y. Gerung, Vonny N. S. Wowor, Christy N. Mintjelungan
}

Program Studi Pendidikan Dokter Gigi Fakultas Kedokteran Universitas Sam Ratulangi, Manado, Indonesia

Email: yuliagerung@gmail.com

\begin{abstract}
Behavior is the second major factor that affects the health status of an individual or society. Good behavior in maintaining oral hygiene will have a positive impact on the status of children's oral health. One of the efforts to reduce the number of caries is through the Usaha Kesehatan Gigi Sekolah (UKGS) program. This study was aimed to obtain the oral health care behavior of elementary school students with UKGS and without UKGS. This was a literature review study. There were four relevant literatures with related topics obtained from different databases, as follows: Google Scholar, PubMed, and Garba Rujukan Digital. The results showed that the UKGS program was effective in increasing the status of students' oral health. Besides education about oral health at schools, parents and the media played some important roles in providing information of oral care. In conclusion, oral health care behavior of elementary school students with and without UKGS were in good category as long as teachers, parents, and internet media as well as print media were involved.
\end{abstract}

Keywords: behavior; oral health; Usaha Kesehatan Gigi Sekolah (UKGS)

\begin{abstract}
Abstrak: Perilaku merupakan faktor kedua terbesar yang berpengaruh terhadap status kesehatan individu atau masyarakat. Perilaku yang baik dalam pemeliharaan kebersihan mulut akan berdampak positif pada derajat kesehatan gigi mulut anak. Salah satu upaya yang dilakukan untuk menurunkan angka karies yaitu melalui program Usaha Kesehatan Gigi Sekolah (UKGS). Penelitian ini bertujuan untuk mengetahui perilaku pemeliharaan kesehatan gigi mulut siswa SD dengan UKGS dan tanpa UKGS. Jenis penelitian ialah literature review. Terdapat empat pustaka yang relevan dengan topik terkait. Pustaka dalam penelitian didapat dari database Google Scholar, PubMed, dan Garba Rujukan Digital. Hasil penelitian menunjukkan program UKGS efektif dalam meningkatkan derajat kesehatan gigi mulut siswa. Pendidikan tentang kesehatan gigi mulut tidak hanya berasal dari sekolah, tetapi orang tua dan media berperan penting dalam memberikan informasi tentang pemeliharaan gigi mulut. Simpulan penelitian ini ialah perilaku pemeliharaan kesehatan gigi mulut siswa SD dengan UKGS dan tanpa UKGS keduanya dalam kategori baik sepanjang adanya keterlibatan guru, orang tua, dan media internet maupun cetak.
\end{abstract}

Kata kunci: perilaku; kesehatan gigi mulut; Usaha Kesehatan Gigi Sekolah (UKGS)

\section{PENDAHULUAN}

Kesehatan merupakan kondisi fisik, mental, dan sosial yang lengkap dan bukan sekedar tidak adanya penyakit atau kelemahan. Kesehatan tubuh berperan penting dalam menjalani aktifitas sehari-hari baik dari segi fisik maupun psikis. Salah satu bagian penting dari kesehatan tubuh ialah gigi dan mulut. Gigi yang berada dalam mulut merupakan salah satu organ tubuh yang memiliki beberapa fungsi; dengan demikian kesehatan gigi mulut merupakan bagian integral dari kesehatan secara keseluruhan. Kesehatan gigi mulut yang terganggu dapat berakibat pada terganggunya fungsi bicara, mengunyah, atau 
fungsi estetik, yang dapat berpengaruh pada aktivitas individu sehari-hari. Gangguan pada kesehatan gigi mulut yang hingga kini masih merupakan masalah yang banyak menyerang masyarakat sejak usia dini hingga dewasa, yakni masalah penyakit karies gigi. ${ }^{1,2}$

Riset Kesehatan Dasar (RISKESDAS) 2018 menunjukkan bahwa 93\% anak Indonesia mengalami karies. Hal ini berarti hanya $7 \%$ anak di Indonesia yang bebas dari masalah karies. Penyakit karies gigi merupakan penyakit yang terkait erat dengan masalah kebersihan gigi mulut anak. Menurut Blum terdapat empat faktor yang merupakan determinan kesehatan, yakni faktor lingkungan, perilaku, pelayanan kesehatan, dan faktor herediter. Faktor perilaku merupakan faktor kedua terbesar yang berpengaruh terhadap status kesehatan individu atau masyarakat. Anak dengan perilaku yang baik dalam pemeliharaan kebersihan mulut akan berdampak positif pada kesehatan gigi mulut dari yang bersangkutan. ${ }^{3-5}$

Anak yang sehat merupakan aset bangsa bagi masa depan, untuk itu Kementerian Kesehatan mencanangkan Indonesia Bebas Karies tahun 2030 mengingat masih tingginya prevalensi karies pada anak. Salah satu upaya konkrit untuk menekan tingginya angka karies gigi, yakni melalui program menyikat gigi yang baik dan benar. Program ini merupakan upaya promotif preventif dengan memberdayakan dokter gigi dan Usaha Kesehatan Gigi Sekolah (UKGS) di seluruh Indonesia.

UKGS adalah usaha memelihara dan meningkatkan kesehatan gigi dan mulut seluruh siswa di sekolah melalui pendidikan kesehatan. Pelayanan kesehatan gigi dan mulut, serta pembinaan lingkungan kehidupan sekolah sehat yang pertama kali dilakukan pada tahun 1951. UKGS merupakan bagian integral dari Usaha Kesehatan Sekolah (UKS) yang melaksanakan pelayanan kesehatan gigi dan mulut secara terencana pada para siswa terutama siswa Sekolah Dasar (SD). Dalam suatu kurun waktu tertentu, hal tersebut diselenggarakan secara berkesinambungan melalui paket UKS. ${ }^{6,7}$ Tingginya prevalensi penyakit gigi dan mulut pada anak dan pentingnya peran UKGS dalam memelihara dan meningkatkan kesehatan gigi dan mulut mendorong penulis untuk meneliti perilaku pemeliharaan kesehatan gigi mulut siswa SD dengan UKGS dan tanpa UKGS.

\section{METODE PENELITIAN}

Penelitian ini merupakan penelitian kualitatif yang bersifat studi pustaka. Penelitian dilakukan pada bulan Mei-Juli 2020 di perpustakaan virtual. Data penelitian merupakan data sekunder berupa hasil penelitian sebelumnya yang berhubungan dengan judul penelitian. Pencarian pustaka berasal dari beberapa database yaitu Google Scholar, PubMed, dan Garba Rujukan Digital. Kriteria inklusi yang digunakan ialah terbitan 10 tahun terakhir, tersedia full text, berbahasa Indonesia atau Inggris. Pustaka yang tidak relevan dengan judul penelitian dieksklusikan dan tidak termasuk sebagai sumber data dalam penelitian.

\section{HASIL PENELITIAN}

Data yang didapatkan untuk penelitian ini bersumber dari buku teks, artikel, dan pustaka, yang diakses dari internet yang membahas mengenai perilaku siswa SD dengan UKGS dan tanpa UKGS. Dalam pencarian referensi, peneliti mendapatkan empat pustaka yang relevan dan sesuai kriteria penelitian. Data elektronik untuk penelitian diperoleh dari beberapa database seperti Google scholar, PubMed, dan Garba Rujukan Digital. Tabel 1 memperlihatkan karakteristik keempat pustaka tersebut.

\section{BAHASAN}

UKGS adalah pelaksana upaya pelayanan kesehatan gigi di sekolah mulai dari pelayanan promotif, preventif, dan kuratif. Tujuan dari program UKGS yaitu meningkatkan derajat kesehatan gigi mulut siswa. Sekolah yang menjalankan program UKGS akan mendapatkan pendidikan kesehatan gigi dari tenaga kesehatan dan guru sehingga diharapkan memiliki siswa dengan perilaku pemeliharaan kesehatan gigi yang lebih baik daripada sekolah yang tidak menjalankan program UKGS. ${ }^{7}$ 
Tabel 1. Karakteristik literatur dalm penelitian ini

\begin{tabular}{|c|c|c|c|}
\hline $\begin{array}{c}\text { Peneliti dan } \\
\text { Tahun }\end{array}$ & Judul & Metode dan Sampel & Ringkasan Hasil \\
\hline $\begin{array}{l}\text { Siregar IHY et al, } \\
2018 .{ }^{8}\end{array}$ & $\begin{array}{l}\text { Perbedaan dari dampak } \\
\text { UKGS mandiri antara } \\
\text { SD Antonius dan SD } \\
\text { Petra Semarang }\end{array}$ & $\begin{array}{l}\text { Deskriptif kuantitatif de- } \\
\text { ngan pendekatan cross } \\
\text { sectional, pengambilan } \\
\text { data menggunakan kue- } \\
\text { sioner pada } 38 \text { sampel }\end{array}$ & $\begin{array}{l}\text { UKGS mandiri yang dilak- } \\
\text { sanakan mampu mening- } \\
\text { katkan kesehatan gigi dan } \\
\text { mulut siswa. }\end{array}$ \\
\hline $\begin{array}{l}\text { Lestari DW, } \\
\text { Indarjo S, } \\
2016 .^{9}\end{array}$ & $\begin{array}{l}\text { Evaluasi penerapan ma- } \\
\text { najemen UKGS dalam } \\
\text { perilaku perawatan gigi } \\
\text { dan mulut siswa seko- } \\
\text { lah dasar }\end{array}$ & $\begin{array}{l}\text { Mixed method analysis } \\
\text { dengan studi evaluasi dan } \\
\text { pendekatan kuantitatif dan } \\
\text { kualitatif, dengan } 213 \\
\text { sampel. }\end{array}$ & $\begin{array}{l}\text { Perilaku siswa dari lima } \\
\text { sekolah baik. UKGS dan } \\
\text { pemeriksaan gigi berjalan } \\
\text { baik. }\end{array}$ \\
\hline $\begin{array}{l}\text { Roza A et al, } \\
2018 .{ }^{10}\end{array}$ & $\begin{array}{l}\text { Perilaku siswa tentang } \\
\text { kesehatan gigi di SD } \\
\text { Negeri 005 Gubung } \\
\text { Malelo Koto Kampar } \\
\text { Hulu tahun } 2017\end{array}$ & $\begin{array}{l}\text { Desktiptif dengan pende- } \\
\text { katan cross sectional, } \\
\text { dengan } 78 \text { sampel }\end{array}$ & $\begin{array}{l}44,9 \% \text { siswa SDN } 005 \\
\text { memiliki pengetahuan cu- } \\
\text { kup. } 51,3 \% \text { siswa memiliki } \\
\text { sikap positif, } 66,7 \% \text { siswa } \\
\text { memiliki tindakan baik. }\end{array}$ \\
\hline $\begin{array}{l}\text { Rompis K et al, } \\
2019 .{ }^{11}\end{array}$ & $\begin{array}{l}\text { Gambaran perilaku pe- } \\
\text { meliharaan kesehatan } \\
\text { gigi mulut dan indeks } \\
\text { plak siswa SD Katolik } \\
\text { Wori }\end{array}$ & $\begin{array}{l}\text { Deskriptif dengan pende- } \\
\text { katan cross sectional. } \\
\text { Pengambilan data meng- } \\
\text { gunakan kuesioner pada } \\
48 \text { sampel. }\end{array}$ & $\begin{array}{l}\text { Perilaku siswa yaitu pe- } \\
\text { ngetahuan, sikap, dan tin- } \\
\text { dakan tergolong baik. }\end{array}$ \\
\hline
\end{tabular}

Penelitian oleh Siregar et $\mathrm{al}^{8}$ dilakukan terhadap dua sekolah di Semarang yang bertujuan untuk membandingkan dampak program UKGS pada siswa kelas I sampai kelas VI. Sampel penelitian berjumlah 38 siswa dari masing-masing sekolah dengan rerata usia 7-12 tahun. Faktor yang dinilai yaitu pengetahuan, sikap, dan tindakan dalam pemeliharaan kesehatan gigi mulut. Hasil penelitiannya mendapatkan rerata pengetahuan, sikap, dan tindakan siswa dari kedua SD berada dalam kategori baik. Menurut penelitian tersebut, program UKGS yang dilaksanakan berpengaruh dalam meningkatkan perilaku dan derajat kesehatan gigi mulut siswa dengan hasil pengetahuan baik $88,6 \%$, sikap baik $85,7 \%$, dan tindakan baik $57,1 \%$. Hasil penelitian tersebut sejalan dengan penelitian oleh Lopez-Nunez et al ${ }^{12}$ di Mexico dan NaseriSalahhour et al $^{13}$ di Iran yang melaporkan bahwa pendidikan kesehatan gigi berbasis sekolah berpengaruh meningkatkan ketrampilan siswa dan program tersebut mudah diimplementasikan pada anak usia sekolah dasar.

Penelitian oleh Lestari dan Indarjo ${ }^{9}$ yang dilakukan di lima sekolah dasar negeri dan swasta di Semarang menunjukkan dari lima sekolah terdapat tiga sekolah yang siswanya berperilaku baik sedangkan dua sekolah yang lain memiliki siswa dengan perilaku pemeliharaan kesehatan gigi sedang. Program UKGS di kelima sekolah tersebut berjalan baik. Beberapa kegiatan yang rutin dilakukan ialah pemberian materi seputar kesehatan gigi dan mulut oleh guru dan petugas kesehatan dari puskesmas dan pemeriksaan gigi diikuti dengan rujukan ke puskesmas jika gigi anak bermasalah. Secara keseluruhan perilaku siswa dalam memeliharan kesehatan gigi mulut, menyikat gigi, dan memanfaatkan layanan kesehatan gigi sudah baik.

Pendidikan kesehatan yang diberikan melalui UKGS merupakan usaha atau kegiatan untuk membantu individu, kelompok atau masyarakat dalam meningkatkan kemampuannya menjaga kesehatan gigi dan mulut dari tidak tahu mengenai nilai-nilai kesehatan menjadi tahu, dari tidak mampu mengatasi masalah-masalah kesehatannya sendiri menjadi mampu. Dari dua sumber data yang ditemukan didapatkan hasil bahwa perilaku pemeliharaan kesehatan gigi siswa SD yang sekolahnya menjalankan 
UKGS berada dalam kategori baik. Hal ini membuktikan bahwa program UKGS efektif dalam proses pembelajaraan kesehatan gigi mulut dan dalam peningkatan derajat kesehatan gigi mulut. ${ }^{7-9}$

Mengenai perilaku pemeliharaan kesehatan gigi mulut siswa SD tanpa UKGS, dalam pencarian data, peneliti mendapatkan dua jurnal yang membahas tentang perilaku pemeliharaan kesehatan gigi mulut dari siswa SD yang sekolahnya tidak menjalankan program UKGS. Beberapa hasil penelitian menunjukkan rerata perilaku siswa berada dalam kategori baik. Program UKGS tidak dijalankan di beberapa sekolah tersebut, namun orang tua dan guru terbukti berperan dalam meningkatkan derajat kesehatan gigi mulut siswa. ${ }^{10,11,14}$

Penelitian oleh Roza et al ${ }^{10}$ dilakukan di Kampar Hulu Riau mengenai perilaku siswa $\mathrm{SD}$, termasuk pengetahuan, sikap, dan tindakan pemeliharaan kesehatan gigi mulut. Teknik pengambilan sampel penelitian ini menggunakan total sampling sehingga didapatkan 78 sampel yang merupakan gabungan dari siswa kelas IV dan V. Hasil penelitian menunjukkan $44,9 \%$ siswa berpengetahuan cukup, $51,3 \%$ siswa memiliki sikap positif, dan $66,7 \%$ siswa bertindak baik dalam pemeliharaan kesehatan gigi mulut.

Rompis et $\mathrm{al}^{11}$ melakukan penelitian di SD Katolik Wori Manado dan melibatkan 48 sampel yang berusia 8-10 tahun. Hasil penelitian menunjukkan perilaku siswa yaitu pengetahuan, sikap, tindakan dalam pemeliharaan kesehatan gigi mulut dalam kategori baik. Perilaku siswa tergolong baik karena informasi tentang kesehatan gigi mulut tidak hanya didapatkan di sekolah tetapi juga melalui media cetak, televisi, internet, dan banyak media informasi lainnya. Hal ini sejalan dengan penelitian Fitri et $\mathrm{al}^{14}$ mengenai hubungan pengetahuan dengan sikap pemeliharaan kesehatan gigi dan mulut siswa Pondok Pesantren Salafiyah Al-Majidiyah. Penelitian ini dilakukan di sekolah yang tidak menjalankan UKGS namun peran guru dan informasi dari internet berpengaruh pada perkembangan perilaku siswa. ${ }^{11,14}$ Walaupun program UKGS tidak dijalankan namun peran orang tua, guru, dan informasi dari internet maupun media lain berperan penting dalam memberikan pendidikan mengenai pemeliharaan kesehatan gigi mulut. ${ }^{14}$

Penelitian ini memiliki keterbatasan dikarenakan kurangnya referensi, perbedaan jumlah sampel penelitian, dan perbedaan usia serta latar belakang populasi dari setiap jurnal. Hasil penelitian dari beberapa sumber yang bervariasi diakibatkan oleh perbedaan usia dan latar belakang sosial ekonomi yang dapat memengaruhi daya tangkap dan proses belajar siswa. ${ }^{10,11,15,16}$

\section{SIMPULAN}

Perilaku pemeliharaan kesehatan gigi siswa SD dengan UKGS dan tanpa UKGS keduanya tergolong baik karena pendidikan tentang kesehatan gigi mulut tidak hanya berasal dari sekolah, tetapi orang tua dan media turut berperan penting dalam memberikan informasi tentang pemeliharaan gigi mulut.

\section{Konflik Kepentingan}

Penulis menyatakan tidak terdapat konflik kepentingan dalam studi ini.

\section{DAFTAR PUSTAKA}

1. World Health Organization (WHO). Definisi Sehat. [cited 2020 Feb 8]. Available from URL: www.who.int.

2. Centers of Control Diseases Prevention. Preventing dental caries with community programs. [cited 2020 May 18]. Available from URL: http://www.cdc.gov/oralhealth/publications/-factsheets/ dental_caries.htm.

3. Badan Penelitian dan Pengembangan Kesehatan. Hasil utama Riskesdas 2018. Jakarta: Kemenkes RI, 2018.

4. World Dental Federation. FDI in Brief. [cited $2020 \mathrm{Feb}$ 25]. Available from URL: http://www.fdiworlddental.org/aboutfdi/fdi-in-brief/fdi-in-brief.aspx.

5. Blum H. Planning for Health, Development and Application of Social Changes Theory. New York: Human Sciences Press, 1974.

6. Kementerian Kesehatan RI. Rencana Kesehatan Gigi dan Mulut Tahun 2015-2019. Jakarta: Kemenkes RI, 2014; p. 43-4.

7. Pedoman Usaha Kesehatan Gigi Sekolah 
(UKGS) (1st ed). Jakarta: Kementerian Kesehatan RI, 2012.

8. Siregar IHY, Supardan I, Sadimin. Perbedaan dampak UKGS mandiri antara SD Antonius dan SD Petra Semarang. Jurnal Kesehatan Gigi. 2018:5(2):60-4.

9. Lestari DW, Indarjo S. Evaluasi penerapan manajemen UKGS dalam perilaku perawatan gigi dan mulut siswa sekolah dasar. Journal of Health Education. 2016:1(2):8-11.

10. Roza A, Ervani, Fitri A. Perilaku siswa tentang kesehatan gigi di SDN 005 Gunung Malelo Koto Kampar Hulu tahun 2017. Jurnal Photon. 2018: 8(2):111-9.

11. Rompis K, Wowor VNS, Mintjelungan CN. Gambaran perilaku pemeliharaan kesehatan gigi mulut dan indeks plak siswa SD Katolik Wori. eBiomedik. 2019: 7(2):98-101.

12. Lopez-Nunez B, Aleksejuniene J, VillanuevaVilchis MDC. School-based dental education for improving oral self-care in Mexican elementary school-aged children. J Health Promotion Pract.
2019:20(5):684-96.

13. Naseri-Salahsour V, Abredari Hamid, Sajadi M, Sabzaligol M, Karimy M. The effect of oral health promotion program on early dental decay in students: a cluster randomized controlled trial. J Caring Sci. 2019:8(2):105-10.

14. Fitri AB, Zubaedah C, Wardani R. Hubungan pengetahuan dengan sikap pemeliharaan kesehatan gigi dan mulut siswa Pondok Pesantren Salafiyah AlMajidiyah. Jurnal Ked Gi Unpad. 2017: 29(2):145-50

15. Sutjipto C, Wowor VNS, Kaunang WPJ. Gambaran tindakan pemeliharaan kesehatan gigi dan mulut anak usia 10-12 tahun di SD Kristen Eben Haezar 02 Manado. eBiomedik. 2013:1(1):697-706.

16. Novita CF, Herwanda., Muhajir. Tingkat pengetahuan kesehatan gigi dan mulut pada guru dan murid SDN 16 (UKGS) dan SDN 46 (tanpa UKGS) di kota Banda Aceh. Jurnal Cakradonya Dent. 2017:9(2):121-6. 